\title{
IMPACT OF NON-ZERO INCIDENT ANGLE TO PROPELLER PERFORMANCE CHARACTERISTICS AND ITS BEM MODEL
}

\author{
J. Hnidka*, D. Rozehnal** ${ }^{* *}$ B. V. Nguyen ${ }^{* * *}$
}

\begin{abstract}
Small unmanned aerial vehicles (SUAVs) typically rely on a fixed pitch propeller to produce required thrust. Knowledge of the propeller performance characteristics can help to properly choose or design an optimal propeller for a given SUAV and its mission. These characteristics can be obtained by a number of methods, with this paper focusing on the so-called blade element Joukowsky model (BEM). The original model was derived for the propeller operating in an axial flow. This paper explains a modified version of the original algorithm to introduce a non-zero incident angle to the calculation. Furthermore, it presents results from the measurement of the Bambula $18 x 8$ fixed pitch propeller in an incident flow and compares the results from the measurement with the calculated data.
\end{abstract}

Keywords: Propeller performance characteristics, Low-Reynolds propeller, incident flow, SUAV, LabVIEW.

\section{Introduction}

As the unmanned aerial vehicles become more and more accessible to public, we can see increase of their application in both military and commercial sectors. It is expected that by 2050 , more than 7 million drones will be operational in the European airspace alone, as predicted by SESAR (2016). Considerable portion of these drones will be small unmanned aerial vehicles (SUAVs), which, as a category, are defined by Army UAS CoE Staff (2010). These SUAVs typically rely on a fixed pitch propeller powered by an electric motor with an onboard battery system as a source of thrust. As the complexity of the mission, where SUAVs can be used, increases, the requirements on their flight performance - especially maximum endurance - increase as well. Because of the limited power supply onboard, it is necessary to improve the efficiency of the overall system to achieve better results.

Fig. 1 demonstrates the increase of the energy density of commercially available battery cells over the past decades. In 2017, the maximum available energy density was roughly around 265 W.h.kg-1 ${ }^{-1}$. Energy density of the gasoline is roughly 13,000 W.h.kg- ${ }^{-1}$. This significant difference diminishes the increased motor efficiency compared to ICE.

To increase the efficiency of the propeller, it is necessary to know the propeller performance characteristics $(\mathrm{PPCH})$. The PPCH can be obtain by a number of methods: numerically, or experimentally. This paper focuses on the blade element Joukowsky model (BEM), which was modified to enable calculations of propellers operating in a non-axial flow by Salga et al. (1977). This model is quick and computationally inexpensive, yet it does produce sufficiently correct results in the axial flow. To investigate its behavior and accuracy at larger incidence angles, a simple experiment in the wind tunnel was designed. The

\footnotetext{
Ing. Jakub Hnidka, Ph.D.: Department of Aircraft Technology, University of Defence; Kounicova 65; 602 00, Brno; CZ, jakub.hnidka@unob.cz

** doc. Ing Dalibor Rozehnal, Ph.D.: Department of Aircraft Technology, University of Defence, Kounicova 65, 602 00; Brno, CZ, dalibor.rozehnal@unob.cz

*** Ing. Van Bang Nguyen, Ph.D.: Department of Air Force and Aircraft Technology, University of Defence, Kounicova 65, 602 00; Brno, CZ, vanbang.nguyen@unob.cz.
} 
measured propeller was then put into the 3D scanner and its exact geometry was used as an input to the BEM model.

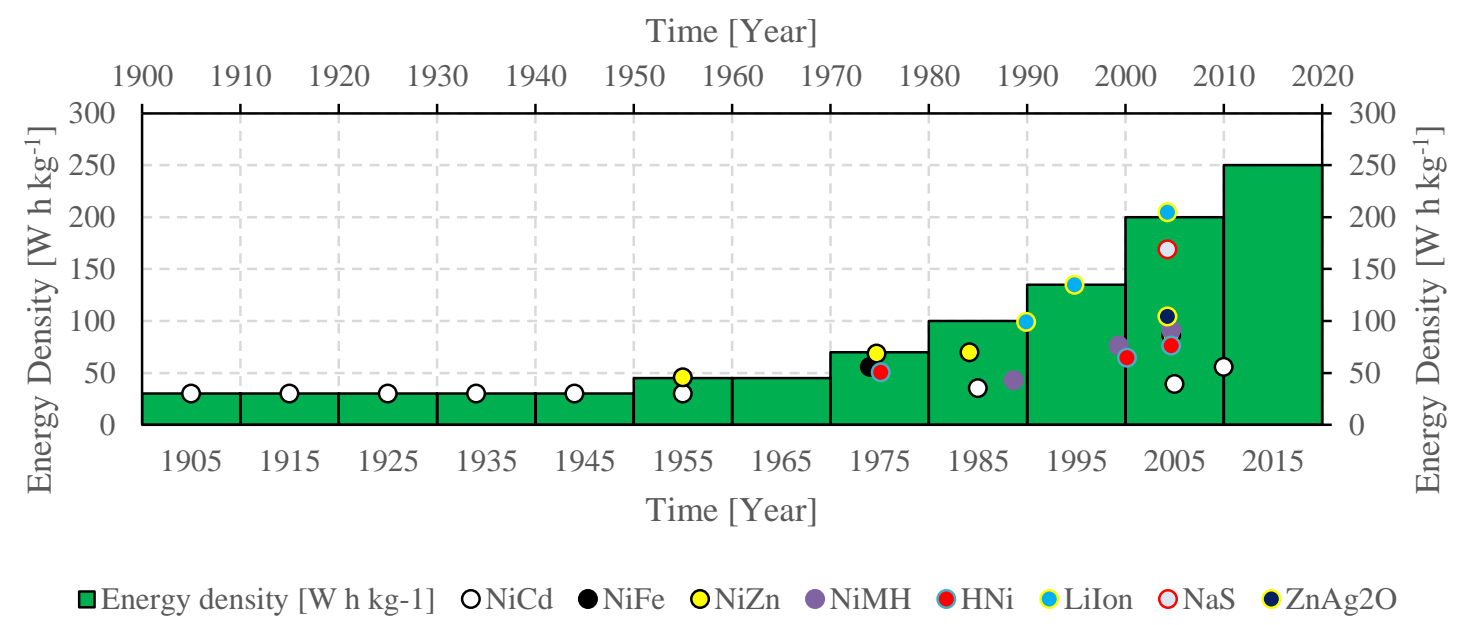

Fig. 1: Energy density of commercially available battery cells over time by Chen-Xi \& Hong (2011)

\section{Blade Element Joukowsky Model}

Joukowsky simplified blade element model represents a propeller with a finite number of blades as a system of vortexes, which produce equivalent forces. The velocity induced by the rotor is calculated from the circulation, and subsequently circulation affects the velocity field around the rotor. The rotor disc is divided into a finite number of blade elements, hence blade element model.

It is assumed, that each blade element has constant geometric and aerodynamic characteristics. Furthermore, the radial component of the passing flow is assumed to be zero (or near zero). Because of this assumption, the fundamental 3D nature of the flow can be simplified and the forces acting on the blade element can be calculated from a 2D airfoil theory. The velocity triangle, from which it is possible to calculate the corresponding force and thrust increment on a given blade element is shown in Fig. 2.

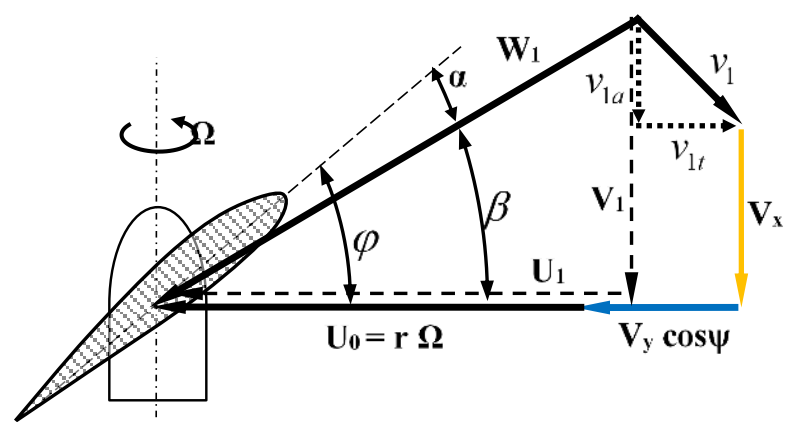

Fig. 2: Joukowsky BEM velocity triangle by Rozehnal (2018)

The local inflow velocity $w_{l}$ is composed from velocities $V_{l}$ and $U_{l}$ with an angle between them equal to the difference between propeller adjustment angle $\varphi$ and local angle of attack (AoA) $\alpha$, as shown in the Fig. 2.

$$
\begin{gathered}
w_{1}=\sqrt{V_{1}^{2}+U_{1}^{2}} \\
\beta=\varphi-\alpha=\arctan \left(V_{1} / U_{1}\right)
\end{gathered}
$$

It can be shown that both $V_{l}$ and $U_{l}$ are dependent on a local circulation $\Gamma$. Moreover, the local circulation $\Gamma$ can be obtained as:

$$
\Gamma=c_{L} c \frac{U_{1}}{\cos (\varphi-\alpha)} \mathrm{D} \Omega
$$


Where $c$ is chord length, $D$ is rotor diameter, $\Omega$ is angular velocity of the rotor and the $C_{L}(\alpha)$ is the lift coefficient.

This algorithm leads to iterative solution of the local circulation $\Gamma$. This calculation typically converges very quickly. However, as seen from the equation (6), the calculation depends on the accuracy of the airfoil lift curve for each blade element. Because the rotor geometry changes along the radius and the local Reynolds number changes as well, each section has a unique polar. The polar data for each section can be obtained either by calculation or by wind tunnel experiments. Typically, these polars are obtained only for a pre-stall region. Nguyen (2016) discussed the requirements for the full polar.

Rozehnal et al. (2018) and MacNeil and Verstraete (2016) compared different methods of obtaining the polar data. While wind tunnel measurements present the most accurate results, due to the variations of both geometry and Reynolds number, it is virtually impossible to obtain all required data only by wind tunnel measurements. XFOIL can be used to calculate the required input polars and it is a sufficiently accurate tool for BEM calculations.

The extrapolation of the polar data was performed by Vieterna-Corrigan method (1982). Further corrections to the calculation, such as Mach number correction and stall delay model were applied to the calculation as discussed by Hnidka (2018). The dynamic stall model, as discussed by Roezhnal et al. (2018) and Nguyen (2018) was not yet implemented in the calculation.

\section{Measurement of the propeller performance characteristics}

The measurement of the propeller performance characteristics of propeller Bambula $18 \times 8$ was performed in the wind tunnel at the University of Defence. The test bed allowed to measure both the propeller thrust and torque at various angles of incidence. The rotational velocity of the propeller was held constant $(n=$ $3500 \mathrm{rpm}$ ) and the velocity in the measurement section was increased from 0 to $30 \mathrm{~m} \cdot \mathrm{s}^{-1}$. The test bed is shown in Fig. 3. The measurement was further described by Nguyen et al. (2018).
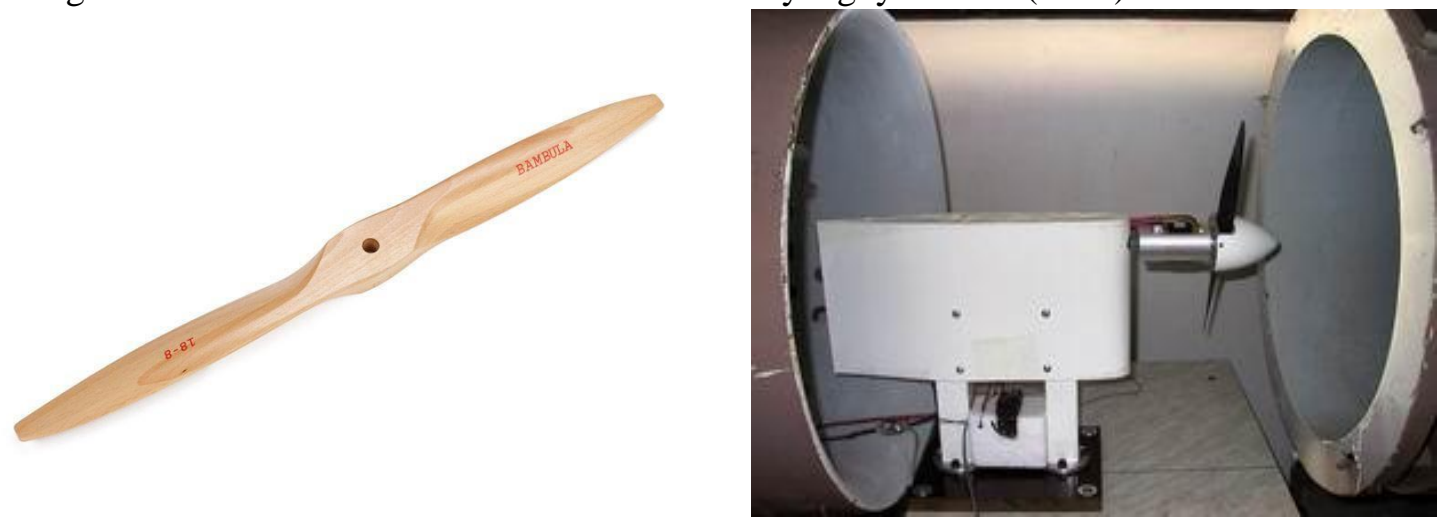

Fig. 3: Propeller Bambula $18 \times 8$ (left) and wind tunnel test bed (right)

\section{Comparison of the results of measurement and calculation}

The measured propeller was scanned by a 3D scanner and the resulting geometry was used as an input to the calculation. The airfoil polars were calculated for every blade section in XFOIL. The resulting propeller performance characteristics for angles of incidence of $20^{\circ}$ and $40^{\circ}$ is shown in Fig. 4.

At lower angles of incidence, the calculated results correspond with the experiment very well. The trust coefficient $c_{T}$ close to the static regime $(\lambda=0)$ is overestimated by the calculation quite significantly. However, as the tip-speed ratio $\lambda$ increases, the accuracy of the method improves considerably.

Both power coefficient $c_{N}$ and efficiency $\eta$ seem to correspond with the measured data reasonably well.

As the incidence angle increases, the accuracy of the method decreases. At $40^{\circ}$, the calculation overestimates the efficiency $\eta$, underestimates the zero thrust point and fails to predict the correct relation of both thrust and power coefficients $\left(c_{T}, c_{N}\right)$. This measurement confirms the hysteresis hypothesis presented by the Rozehnal et al. (2018) At larger angles of incidents, the static polars calculated by XFOIL 
used for the BEM calculation are no longer sufficient. The periodic change of the local angle of attack causes a phenomenon called dynamic stall, which can considerably alter the airfoil polars.

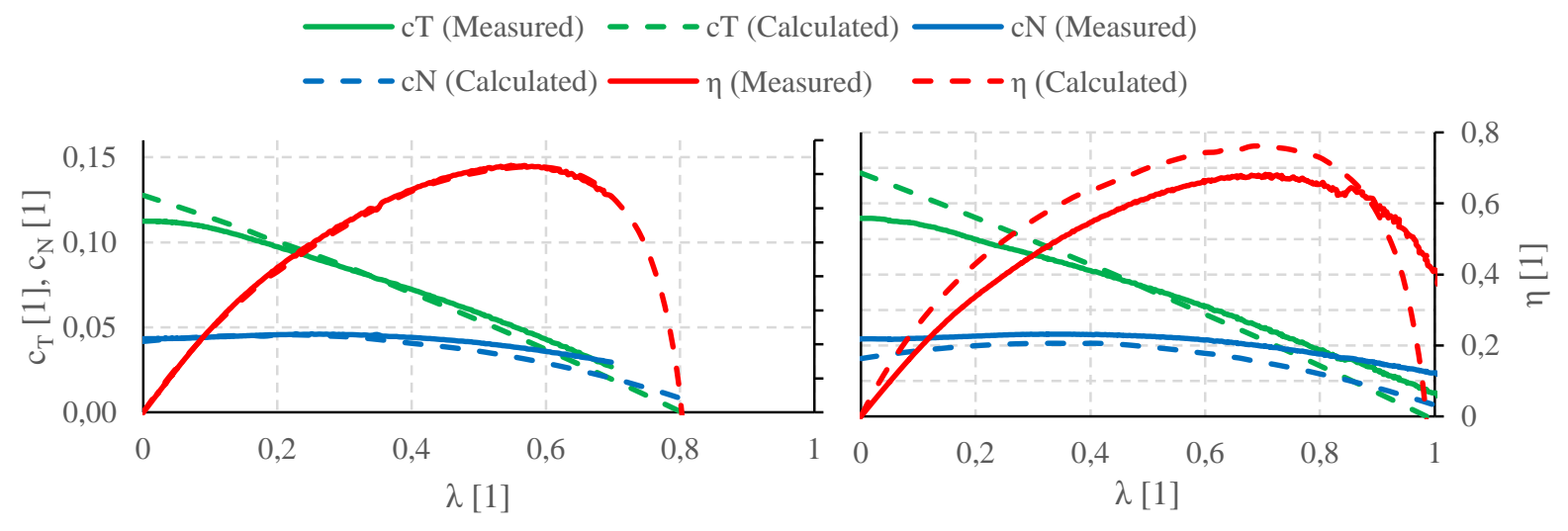

Fig. 4: PPCH with incidence angle of $20^{\circ}$ (left) and $40^{\circ}$ (right)

\section{Conclusion}

This paper presents a BEM model, which can be used to calculate the PPCH for propeller operating in an incident flow. Furthermore, it presents a test bed in a wind tunnel, which was used to verify the model. The mapped propeller was Bambula 18x8. While at low values of incidence, the calculated PPCH was within a reasonable margin of error compared to the measurement, as the angle of incidence increased, the error increased as well. This confirms the hypothesis about the dynamic stall and a further revision of the calculation model is, thus, needed.

\section{Acknowledgement}

This research was conducted in cooperation with company TECHNOFIBER.

\section{References}

Army UAS CoE Staff. (2010). "Eyes of the Army" U.S. Army Roadmap for Unmanned Aircraft Systems 2010-2035. Fort Rucker, Alabama: U. S. Army UAS Center fo Excellence (ATZQ-CDI-C).

Hnidka, J. (2018). Determination of the flight performance of a hybrid-wing UAV. Dissertation. Brno: University of Defence.

Chen-Xi, Z., and Hong, L. (2011). Thermodynamic analysis on energy densities of batteries. Energy \& Environmental Science.

Nguyen, V.B., Rozehnal, D., Hnidka, J., Pham, VU (2018) Influence of yaw on propeller aerodynamic characteristics. EFM17-Experimental fluids mechanics 2017. Mikulov: EPJ Web of Conferences.

Nguyen, V.B. and Rozehnal, D. (2016) Determine $360^{\circ}$ polar for calculation of wind turbines. $17^{\text {th }}$ Int. Conf. Transfer 2016, Trenčín, pp.1-7.

Nguyen, V. B. (2018). Determination of Propeller Aerodynamic Characteristics in Yaw With the Influence of the Unsteady Flow around Blades. Dissertation. Brno: University of Defence in Brno.

MacNeill R. and Verstraete, D. (2016) Blade element momentum theory extended to model low Reynolds number propeller performance. $20^{\text {th }}$ Australasian Fluid Mechanics Conference.

Rozehnal, D., Nguyen, V., \& J., H. (2018). Hysteresis assumptions for propeller in yaw in close stall conditions. ENGINEERING MECHANICS 2018 (s. 721-724). Svratka: Institute of Theoretical and Applied Mechanics of the Czech Academy of Sciences.

Salga, J., Sveda, J., \& Horeni, B. (1977). Výpočet aerodynamických charakteristik šikmo ofukované vrtule. Brno: VAAZ.

SESAR Joint Undertaking. (2016). Demonstrating RPAS integration in the European aviation system. Luxembourg: Publication Office of the European Union. doi:10.2829/013869

Viterna, L. A. and Corrigan, R. D. (1982) Fixed pitch rotor performance of large horizontal axis wind turbines. Large Horizontal-Axis Wind Turbines. NASA Conference Publication 2230, Cleveland, pp. 69-85. 